\title{
Effects of Tillage Methods and Vegetation Coverage on Reducing Runoff and Soil Erosion
}

\author{
Ma Changchen ${ }^{1,2,3 *}$, Wang Ran ${ }^{1,2,3}$, Li Qingyuan ${ }^{1,2,3}$, and Lu Fangchun ${ }^{1,2,3}$ \\ ${ }^{1}$ Zhejiang Guangchuan Engineering Consulting Co. Ltd., Hangzhou, Zhejiang 310020, China \\ ${ }^{2}$ Zhejiang Institute of Hydraulics and Estuary, Hangzhou, Zhejiang 310020, China \\ ${ }^{3}$ Zhejiang Key Laboratory of Water Disaster Prevention and Reduction, Hangzhou 310020, China
}

\begin{abstract}
To study the characteristics of runoff and soil erosion of natural rainfall conditions, five standard runoff plots were set up in our experiment, and different tillage methods and vegetation coverage types were set up. The 58-month monthly precipitation data and 44-month runoff plot observation data from 2013 to 2017 were analysed. The results show that: 1) The monthly precipitation fluctuates significantly, ranging from $13 \mathrm{~mm}$ to $683.5 \mathrm{~mm}$. The precipitation is unevenly distributed over the year. The largest average monthly precipitation is in June and the smallest is in January. Rainfall is mainly concentrated in the spring and summer. The precipitation from March to June accounts for $58.0 \%$ of the annual rainfall. 2) There is a positive correlation between runoff depth and precipitation in each runoff plot $\left(\mathrm{R}^{2}=0\right.$. 5101 0. 6676, Sig. $<0.01)$; 3) There is also a positive correlation between soil loss and precipitation $\left(\mathrm{R}^{2}=0.424 \sim 0.558\right.$, Sig. $<0.01$ ); 4) The amount of soil loss and the runoff depth increase with increasing rainfall. The runoff plot without any vegetation cover or farming measures increase the most. While the one with horizontal steps and shrubs, or a combination of arbor and grass increase the slowest, indicating that they have the best effect of reducing runoff and soil loss.
\end{abstract}

\section{Introduction}

The red soil hilly region (RSHR), located in a subtropical monsoon climate, is the most important strategic agricultural and economic region in China. The soil texture is heavy with poor water permeability. There is often a heavy rainfall precipitation and intensity here. As a result, RSHR is one of the most serious soil erosion areas in China [1-4]. Soil erosion has seriously affected the sustainable development of agriculture and economy in the entire region $[5,6]$.

Rainfall is a necessary condition for runoff and soil erosion. The amount of runoff and soil erosion depend on rainfall precipitation and intensity. At the same time, tillage methods and vegetation coverage type have an important impact [1,3]. Using the simulated rainfall methods, Wang et al. studied the runoff and soil loss characteristics of 8 common land-use types under different rainfall conditions. The results showed that the runoff and soil loss of different land use types are significantly different. Orchards with soil and water conservation measures (SWCMs) have the best water and soil conservation effect, while bare land has the largest runoff [7]. In the study of Duan et al., four groundcover managements (i.e., control bare land, orchard with no cover, orchard with grass cover and orchard with cover crops) were used to analyse runoff and erosion characteristics related to extreme and ordinary rainfalls in RSHR. Ground cover plant management is an important factor affecting the runoff and soil erosion process of orchards [8]. Chen et al. conducted a meta-analysis of 498 field plots covering 53 sites in the RSHR. SWCMs involving erosion control $(92 \%)$ had a greater efficiency than those focusing on runoff reduction $(73 \%)$. The implementation of combined measures was more effective than single measures for reducing runoff and soil loss [9].

We observed the runoff plots under different tillage methods and vegetation coverage types to study its impact on runoff and soil erosion, the characteristics of soil and water loss, and provide theoretical basis for soil and water conservation in RSHR.

\section{Materials and methods}

\subsection{Overview of the study area}

The study area is located in Changshan County, Quzhou City, Zhejiang Province, which belongs to the Qiantang River Basin. The annual average temperature is $17.7^{\circ} \mathrm{C}$. The annual precipitation is $1319-2724 \mathrm{~mm}$, and the annual average precipitation is $1858 \mathrm{~mm}$, of which erosive rainfall $(\geqslant 12 \mathrm{~mm})$ accounts for $78.3 \%$ of the total annual rainfall. The annual average relative humidity is $76 \%$, and the annual average frost-free period is 279 days, the annual average total sunshine

\footnotetext{
* Corresponding author: $\underline{\operatorname{mcc} 0102 @ 163 . c o m}$
} 
hours are 1731.2 hours. It belongs to the subtropical monsoon climate.

\subsection{Experimental design}

A total of 5 standard runoff plots were set up in the experiment, with a horizontal projection area of $100 \mathrm{~m} 2$ $(5 \mathrm{~m} \times 20 \mathrm{~m})$, a slope of $5^{\circ}$, and the soil was all red soil. Under each runoff plot, there are water collection troughs and runoff ponds for collecting runoff and soil from the plot. To ensure that the underlying surface conditions of each treatment are the same. Every treatment adopts the uniform management method. The treatments are as follows (October 2017): treatment A, horizontal steps + tea trees (5 years, 0.9 meters high, vegetation coverage is $60 \%)$; treatment $\mathrm{B}$, slop+ grapefruits (5 years, 2.1 meters high, vegetation coverage is $80 \%$ ); treatment $\mathrm{C}$, slop+ grapefruits + grass (5 years, 2.1 meters high, vegetation coverage is $80 \%$ ); treatment $\mathrm{D}$, horizontal steps + grapefruits (5 years, 2.1 meters high, vegetation coverage is $80 \%$ ); treatment $\mathrm{E}$, slop + without vegetation coverage (vegetation coverage is 0$)$.

\subsection{Data analysis}

Analyse the data of 58 consecutive months of rainfall from March 2013 to December 2017, and the data of 44 months with runoff and soil loss in 5 runoff plots over the same period (among which June 2017 was not sampled in time; No. 5 treatment From March to May 2013, No. 1 treatment in May 2015 and May 2016 due to the damage of the water collection troughs, data is not included), the experiment data are all from natural rainfall events. Use Microsoft Excel 2010 software for data processing and drawing.

\section{Results and analysis}

\subsection{Analysis of rainfall characteristics}

Analysis of the 58-month monthly precipitation shows that the monthly precipitation fluctuates significantly, ranging from $13.0 \mathrm{~mm}$ to $683.5 \mathrm{~mm}$. The precipitation is unevenly distributed over the year, and the monthly precipitation accounts for the annual ratio between $3.07 \%$ and $24.20 \%$. The average monthly precipitation is the largest in June, reaching $500.7 \mathrm{~mm}$, and the coefficient of variation (CV) is the smallest, only 0.27 . The smallest is in January, only $63.6 \mathrm{~mm}$. Rainfall is mainly concentrated in spring and summer. The precipitation from March to June accounts for $58.0 \%$ of the annual precipitation, and the rainfall from March to August accounts for $71.6 \%$ of the annual precipitation.

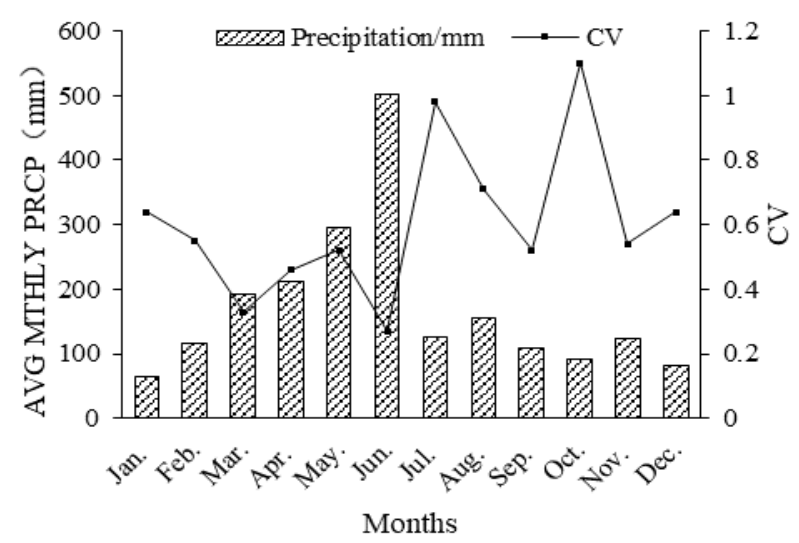

Fig. 1. Monthly distribution and CV of rainfall during 2013-2017.

\subsection{Variation characteristics of runoff depth with rainfall}

Perform linear regression analysis on runoff depth and rainfall. It can be seen from Figure 2 that there is a good positive correlation between runoff depth and rainfall in each plot $\left(\mathrm{R}^{2}=0.5101 \sim 0.6676\right.$, Sig. $\left.<0.01\right)$. The slope of the regression equation of each runoff plot is $\mathrm{E}>\mathrm{D}>\mathrm{B}>$ $\mathrm{A}>\mathrm{C}$, the runoff depth increases with rainfall, and the growth rate of $\mathrm{E}$ is much larger than other treatments. Indicating that with the increase of rainfall, it is easy to produce runoff in the bare land along the slope without any SWCM. In other treatments, due to the effects of tillage methods or vegetation cover, the runoff depths were reduced to varying degrees. The runoff depths of $\mathrm{C}$ and $\mathrm{A}$ increased the slowest with rainfall, indicating that the combination of the arbor and grass (C) and horizontal shrub plots (A) had the best effect on reducing runoff. The $\mathrm{R}^{2} \mathrm{~s}$ are all greater than 0.5 , indicating that the runoff generation in RSHR is mainly stored-full runoff, because stored-full runoff has a great relationship with rainfall, and other factors have relatively little influence. Over-infiltration runoff is just the opposite. RSHR is located in a humid area, which meets the conditions for stored-full runoff.

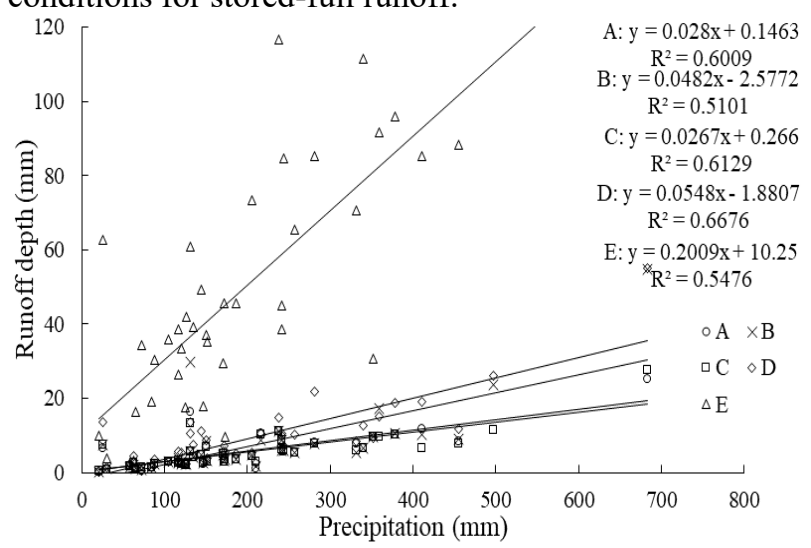

Fig. 2. The relationship between runoff depth and rainfall.

3.3 Variation characteristics of soil loss with rainfall 
Perform linear regression analysis on the amount of soil loss and rainfall. It can be observed in Figure 3 that there is also a positive correlation between soil loss and rainfall in each plot $\left(\mathrm{R}^{2}=0.2748 \sim 0.4585\right.$, Sig. $\left.<0.01\right)$. The slope of the regression equation of each runoff plot is $\mathrm{E}>\mathrm{D}>\mathrm{B}>\mathrm{C}>\mathrm{A}$, which is almost consistent with the relationship between runoff depth and rainfall. The amount of soil loss increases with rainfall, among which the increase of $\mathrm{E}$ was the most significant, while A and C increased the slowest. However, the $\mathrm{R}^{2}$ is usually smaller than that of runoff depth-rainfall. After runoff is generated, soil particles on the slope are carried and lost. In this process, it will also be affected by soil texture, surface morphology, and vegetation coverage. The generation of runoff has a certain relationship with rainfall characteristics, vegetation interception, soil moisture, etc. This also shows that tillage methods and vegetation cover can reduce runoff and soil erosion. While $\mathrm{A}$ and $\mathrm{C}$ increased the slowest. However, the $\mathrm{R}^{2}$ is usually smaller than that of runoff depth-rainfall. After runoff is generated, soil particles on the slope are carried and lost. In this process, it will also be affected by soil texture, surface morphology, and vegetation coverage. The generation of runoff has a certain relationship with rainfall characteristics, vegetation interception, soil moisture, etc. This also shows that tillage methods and vegetation cover can reduce runoff and soil erosion.

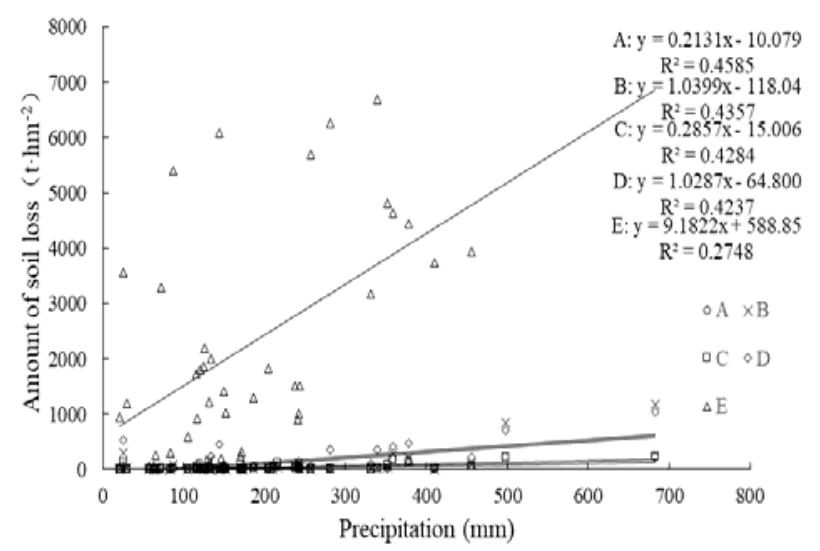

Fig. 3. The relationship between soil loss and rainfall.

\subsection{Soil loss-runoff depth regression analysis}

The regression analysis of the soil loss and runoff depth of each plot was performed through linear regression, and the linear equation was fitted. It can be seen from Table 1 that there is a good correlation between the amount of soil loss and runoff depth in each plot, and the determination coefficient $\mathrm{R}^{2}$ is $0.5870 \sim 0.7636$, and the Sig. is less than 0.01 . The slope of the regression equation of each runoff plot is $\mathrm{E}>\mathrm{B}>\mathrm{D}>\mathrm{C}>\mathrm{A}$, which is basically consistent with the relationship between runoff depth/soil loss and rainfall. With the increase of runoff depth, the amount of soil loss in the bare land along the slope increased the most, while the growth of the combination of the arbor and grass (C) and horizontal shrub plots (A) grew the slowest. The generation of slope runoff is the main driving force that causes soil erosion on the slope. After runoff producing, the soil particles on the slope are carried and lost by the runoff, which gradually increases the sand content of the runoff. After rills appear on the slope, the soil erosion will increase rapidly, and the sediment content of the runoff will also increase.

Table 1. Linear regression equation of soil loss and runoff depth in different runoff plots.

\begin{tabular}{|c|c|c|c|}
\hline Treatments & $\begin{array}{c}\text { Linear regression } \\
\text { equation }\end{array}$ & $\mathbf{R}^{2}$ & Sig. \\
\hline $\mathrm{A}$ & $\mathrm{y}=6.6735 \mathrm{x}-6.0713$ & 0.5870 & 0.000 \\
\hline $\mathrm{B}$ & $\mathrm{y}=20.386 \mathrm{x}-54.090$ & 0.7636 & 0.000 \\
\hline $\mathrm{C}$ & $\mathrm{y}=10.334 \mathrm{x}-15.739$ & 0.6508 & 0.000 \\
\hline $\mathrm{D}$ & $\mathrm{y}=20.125 \mathrm{x}-41.680$ & 0.7282 & 0.000 \\
\hline $\mathrm{E}$ & $\mathrm{y}=38.110 \mathrm{x}+476.560$ & 0.3489 & 0.000 \\
\hline
\end{tabular}

\section{Conclusion and discussion}

The monthly precipitation in the experimental area for 58 months showed a clear fluctuation trend, ranging from $13 \mathrm{~mm}$ to $683.5 \mathrm{~mm}$. The precipitation is unevenly distributed over the year. The average monthly precipitation is the largest in June, reaching $500.7 \mathrm{~mm}$, and the smallest is in January, only $63.6 \mathrm{~mm}$. Rainfall is mainly concentrated in the spring and summer, and the precipitation from March to June accounts for $58.0 \%$ of the annual rainfall.

The runoff depth is positively correlated with rainfall. The linear regression determination coefficient $\mathrm{R}^{2}$ is $0.5101 \sim 0.6676$, and Sig. is less than 0.01. As rainfall increases, runoff depth also increases. The runoff depth of the bare land along the slope increased the most, while the combination of the arbor and grass and horizontal shrub plots grew the slowest, indicating that it has the most obvious effect on reducing runoff.

The amount of soil loss is significantly corelated with rainfall. The linear regression determination coefficient $\mathrm{R}^{2}$ is $0.2748 \sim 0.4585$, and Sig. is less than 0.01 . The amount of soil loss increases with the increase of rainfall. The amount of soil loss on the bare land along the slope increases the most, while the combination of the arbor and grass and horizontal shrub plots grew the slowest. The change trend is similar to the relationship of runoff depth to rainfall, but the $\mathrm{R}^{2}$ is usually smaller. This shows that the bare land along the slope is the easiest to produce soil erosion under rainfall conditions, and the combination of the arbor and grass and horizontal shrub plots can reduce runoff and soil loss.

The amount of soil loss in each runoff plot is positively correlated with the depth of runoff. The coefficient of determination of linear regression $\mathrm{R}^{2}$ is $0.5870 \sim 0.7636$, and Sig. is less than 0.01 . With the increase of runoff depth, the amount of soil loss in the bare land along the slope increased the most, while the 
combination of the arbor and grass and horizontal shrub plots grew the slowest.

\section{References}

1. J.Z. Liang, Res. Soil Water Conserv. 22, 95-99 (2015)

2. J.Z. Liang, Res. Soil Water Conserv. 22, 95-99 (2015)

3. N. Zhang, Q. Zhang, Y.Q. Li, M.S. Zeng, W. Li, C.Y. Chang, Y.R. Xu, C.B. Huang, Sustainability 12, $1146(2020)$

4. S.Y. Peng, Z.J. Gu, P. Xiu, Res. Soil Water Conserv. 22, 25-29 (2013)

5. B. Huang, Z.J. Yuan, D.Q. Li, X.D. Nie, Z.Y. Xie, J.Y. Chen, C. Liang, Y.S. Liao, T. Liu, Sci. Total Environ. 650, 313-320 (2019)

6. J.Z. Liang, Bull. Soil Water Conserv. 35, 159-163 (2015)

7. Q.G. Zhao, G.Q. Huang, Y.Q. Ma, Acta Ecol. Sin. 33, 7615-7622 (2013)

8. B.W. Wang, S.S. Xiao, G.H. Zhang, J. Yang, L.C. Zhang, Agr. Eng. And Sustainability 28, 239-243 (2012)

9. J. Duan, Y.J. Liu, J Yang, C.J. Tang, Z.H. Shi, J. Hydrol. 582, 124290 (2020)J. Chen, H.B. Xiao, Z.W. Li, C. Liu, K. Ning, C.J. Tang. Sci. Total Environ. 735,139517 (2020) 